Artículos

\title{
Gualeguay, la conformación de su paisaje $\mathrm{e}^{[1]}$
}

\section{Gualeguay, the conformation of its landscape}

Garay*, Diego

\author{
Diego Garay* \\ dgarayh@gmail.com \\ Laboratorio de Urbanismo y Arquitectura. Instituto \\ de Arquitectura. Universidad Nacional de San Martín, \\ Argentina
}

\section{Estudios del Hábitat}

Universidad Nacional de La Plata, Argentina

ISSN: 2422-6483

Periodicidad: Semestral

vol. 18 , núm. 2, 2020

aefau@fau.unlp.edu.ar

\section{Recepción: 09 Diciembre 2019}

Aprobación: 18 Junio 2020

Publicación: 30 Diciembre 2020

URL: http://portal.amelica.org/ameli/ jatsRepo/158/1581621002/index.html
Resumen: Se estudia el caso de la Ciudad de Gualeguay, Entre Ríos, desde sus orígenes hasta las primeras décadas del siglo XX. Utilizando herramientas clásicas de la lectura de paisajes, detectamos los elementos espaciales que permiten leer la estructura urbana en formación de esa ciudad moderna, y el proceso de consolidación como sistema socio-ecológico.

Palabras clave: Gualeguay, estructura urbana, metodología, paisaje.

Abstract: We analyze the case of the City of Gualeguay, Entre
Ríos, from its origins to the first decades of the XX century.
Using classic landscape reading tools, we recognize the spatial
elements that show us the urban structure of the city, as we aim to
identify the process of consolidation as a socio-ecologic system.

Keywords: Gualeguay, urban structure, methodology, landscape.

\section{(c) $(1) \Theta \Theta$}

Esta obra está bajo una Licencia Creative Commons AtribuciónNoComercial-SinDerivar 4.0 Internacional.

\section{INTRODUCCIÓN}

La idea de ciudad como un sistema socio-ecológico nos ayuda a interpretar a la ciudad como un sistema complejo, que se vincula con el concepto de territorialidad planteado por Demateis, en cuanto "mediación simbólica, cognoscitiva y práctica que la materialidad de los lugares ejerce sobre el comportamiento social." (Demateis, 1999), a lo que Watsuji llama Fûdosei y que Berque tradujo como mediance o tejido de relaciones mediales: ecológicas, tecnológicas y simbólicas, o a la idea de Corboz cuando propone que un "lugar" no es dato sino el resultado de una condensación.

Desde esta óptica medial y de conexiones múltiples, proponemos estudiar el paisaje urbano de los orígenes de la ciudad de Gualeguay con un doble objetivo. Por un parte, aplicar una forma de análisis que contribuya a la comprensión de ese sistema complejo, y por la otra, enfatizar la observación sobre el espacio desde la interescalaridad y sus vinculaciones.

Las metodologías propuestas por Kevin Lynch para el análisis urbano desde una perspectiva perceptual y morfológica, por Forman desde la ecología, donde el territorio se puede leer en un red de nodos y corredores, inclusive por Ian Mc Harg que traza la vinculación entre capas temáticas superpuestas, son herramientas clásicas en la lectura de paisajes, sin embargo, su aplicación -con ciertas adaptaciones- continúa siendo efectiva 
y pertinente cuando de primeras lecturas se trata, y en particular en la ciudad histórica. En un momento donde la urbanística carece de métodos definidos para la leer la ciudad actual, revisar la ciudad histórica y sus métodos de lecturas, podrían servir como punta del ovillo.

Desde este marco conceptual y metodológico analizaremos la Ciudad de Gualeguay desde sus orígenes hasta las primeras décadas del siglo XX, deteniéndonos primeramente en algunos aspectos relevantes, que denominamos las condiciones de partida, como son ciertas características del subsistema natural, la impronta de los pueblos originarios y la etapa fundacional, y luego desarrollaremos una metodología de análisis urbano utilizando cinco categorías: límites, caminos, nodos, hitos y ámbitos, intentado descifrar la estructura urbana que sostiene la materialidad de ese sistema complejo, dentro del periodo de estudio.

\section{CONDICIONES DE PARTIDA}

\section{El subsistema natural}

El territorio de la ciudad de Gualeguay se encuentra en una zona de transición (ecotono) entre las ecoregiones Pampa, y Delta e Islas del Paraná. Presenta un clima templado, con viento húmedo predominante del nor-este, con precipitaciones abundantes a partir de los meses de febrero y marzo.

El relieve muestra una pendiente de norte a sur hacia el delta, que se va acentuando desde los $13 \mathrm{~m}$ en el límite de la ciudad, a $10 \mathrm{~m}$ en el centro, y hasta los $4 \mathrm{~m}$ en las islas.

El río Gualeguay (Figura 1) abarca una cuenca de $20.450 \mathrm{~km}^{2}$ y una longitud de $486 \mathrm{~km}$, nace en la norteeste de la Provincia, y desemboca en el río Paraná Pavón. Es un río poco profundo no navegable, con múltiples afluentes y con un cauce superior angosto y encajonado que luego se ensancha a partir de Rosario Tala alcanzando los $300 \mathrm{~m}$. En ocasiones provoca grandes inundaciones como las registradas en 1905, 1914, 1959, y en las últimas décadas. Completa la fisonomía de la cuenca, la poca profundidad de las aguas subterráneas, que se encuentran entre los 10 m y 15 m, y su localización dentro de la cuenca del acuífero guaraní.

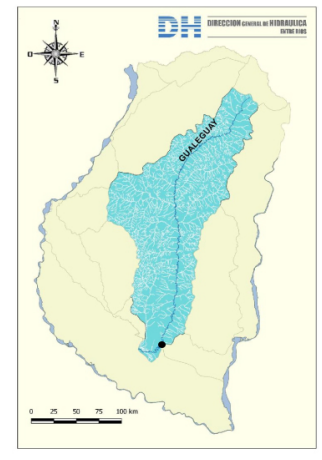

FIGURA 1

MAPA DE LA CUENCA DEL RÍO GUALEGUAY.

FUENTE: DIRECCIÓN HIDRÁULICA DE ENTRE RÍOS, 


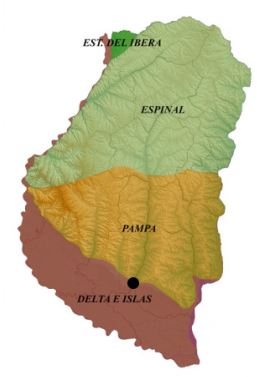

FIGURA 2

MAPA DE ECO-REGIONES

FUENTE: DIIRECCIÓN HIDRÁULICA DE ENTRE RÍOS,

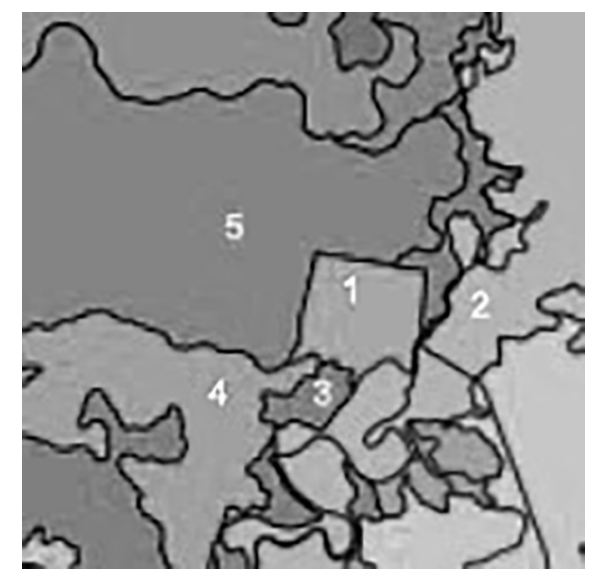

FIGURA 3

MAPA DE SUELOS DE LA CIUDAD DE GUALEGUAY Y SU ENTORNO.

FUENTE: ELABORACIÓN PROPIA EN BASE A LA CARTA DE SUELOS DE ENTRE RÍOS, INTA, 2018.

La Eco-región Delta e Islas del Paraná (Figura 2), comprende el valle de inundación del río Paraná y está formada por montes, pajonales y lagunas que dependen de la dinámica fluvial, alternando inundaciones con incendios de pajonales durante las sequías, en cambio, la subregión Pampa Entrerriana, comprendida dentro de la Eco-región Pampeana, es relativamente homogénea, caracterizada por la presencia de un suelo húmico rico de materia orgánica (molisoles) muy apto para la agricultura.

Tomando como referencia el Mapa de Suelos, realizado por el INTA (2018) (Figura 3) y teniendo presenta que a cada tipo de suelo le corresponde una unidad geomorfológica y un ecosistema determinado, la ciudad de Gualeguay (1), se encuentra rodeada por el este y sur por partes bajas, albardones y esteros (2), terrazas arenosas con napa poco profunda (3), y áreas cóncavas y deprimidas con anegamiento (4), todas con baja productividad de 1 a 5 puntos, representativas de la eco-región Delta e Islas del Paraná, en cambio al norte y oeste, se presenta la llanura Loessica (5), con un índice de productividad de 34 puntos.

La flora de la Eco-región Pampeana, es caracterizada por el pastizal templado y los talares en barrancas, y la fauna se compone por mamíferos, reptiles y aves, que encuentran su refugio bajo tierra o entre los pastizales.

Por otra parte, la flora de la Eco-región Delta e Islas del Paraná se encuentra representada por bosques y arbustales, sobre los albardones en las costas, pajonales y pastizales, en el interior de las islas, e hidrófilas y acuáticas, en lagunas y costas. Toda la eco-región se caracteriza por una gran diversidad de especies de mamíferos, anfibios, peces y aves. 


\section{Lospueblos originarios}

El territorio de la ciudad de Gualeguay presentaba una significativa interacción étnica en el período prehispánico. Mocoretás, Corondas, Chañas-Timbúes, habitaban las costas del Paraná, Guaraníes, principalmente las islas del Delta, y Charrúas ocupaban la zona de Entre Ríos y las costas del río Uruguay. Todos estos grupos eran nómadas, vivían de la caza, la pesca y la recolección, salvo los guaraníes, que eran seminómades y poseían conocimientos agrícolas.

La alimentación consistía en carne, producto de la caza: ñandú, ciervos, carpinchos, peces, y frutas silvestres. Luego el ganado vacuno y el equino, introducido por los conquistadores, se sumó a sus recursos.La familia, era generalmente poligámica, el trabajo doméstico recaía sobre las mujeres, mientras que los hombres se dedicaban a la caza, a la pesca, y a la guerra.Prácticamente carecían de organización política estable, solamente reconocían a un jefe de tribu "el cacique".

Los charrúas en el río Gualeguay fueron descritos como grupos móviles que utilizaban arcos y boleadoras como instrumentos de caza de venados y ñandúes, como también, el uso de canoas para trasladarse en un amplio radio de acción hasta mediados del siglo XVII, cuando aumentaron su movilidad con la incorporación del equino. Hubo una intensa interacción entre grupos charrúas, chaná y guaraníes, reflejada en las alianzas para la guerra y el intercambio de información, bienes y personas, condición que les permitió realizar una fuerte resistencia ante los colonizadores, (Apolinaire, 2016).

\section{El surgimiento de la ciudad. Etapa Fundacional}

La creación del virreinato del Río de la Plata en 1776, surge como una de las respuestas a la crisis generada por la participación de España aliada a Francia en la Guerra de los Siete Años (1756-1763). En ese conflicto la alianza anglo-portuguesa intento invadir las posesiones españolas del estuario del Río de la Plata (1763), incrementando el problema fronterizo con el Imperio Portugués - Colonia del Sacramento frente a Buenos Aires fue representativo de dicha situación.

Por otra parte, la llegada de los británicos a la costa sur del atlántico e Islas Malvinas (1764), junto a exploradores y comerciantes que buscaban la conexión con Oriente por el Estrecho de Magallanes, y la pesca en las aguas del sur, incentivo el proyecto de controlar la Patagonia. En esa coyuntura, el Rey de España Carlos III (1716-1788) incrementó la defensa en las colonias americanas e impartió una serie de reformas con el objeto de obtener un mayor control político-administrativo, y un desarrollo económico que debía ser capital para la revitalización del imperio. La instauración del virreinato en 1776, con centro en Buenos Aires, la reforma mercantil de 1778 y la creación de las intendencias en 1782, son algunas de las estrategias para consolidar un poder centralizado con mayor control de unidades territoriales menores, pero estratégicas. Los virreyes y los intendentes crecieron en poder, aumento la presencia de los ingenieros militares, y los cabildos se sometieron a ellos, (Favelukes, 2011).

En 1715 existía una capilla rural en la Bajada Grande, actual Paraná, y cercano a ella se originó un asentamiento espontaneo en 1720. Cuarenta años después, junto al arroyo Nogoyá, se estableció otro asentamiento que junto a la Bajada Grande conformaban un territorio que dependía del Cabildo y Parroquia matriz de Santa Fe, y de la sede Episcopal de Buenos Aires.

Más allá de esta porción occidental que llegaba hasta Nogoyá, el Cabildo no podía ejercer su jurisdicción quedando un extenso territorio hacia el río Uruguay en poder de los indígenas. Luego de 1750, cuando el Gobernador Andonaegui ordenó la captura de los charrúas y la expulsión de los guaraníes hacia la colonia portuguesa, estas tierras realengas pasaron al dominio de terratenientes como Wright, Ormaechea y Zuñiga en 1777. 
Hacia 1773 la Bajada Grande era una posta del camino a Paraguay o "Carrera al norte" y a las ex misiones Jesuíticas ${ }^{[2]}$, partiendo desde Buenos Aires, con cruce del río Paraná desde Santa Fe, y luego rumbo a Santa Lucia y Corrientes, siendo las tres, sedes de Administración del Correo.

En 1778 el nuevo obispo de Buenos Aires, Monseñor Sebastián Malvar y Pinto, informó al Virrey Vértiz acerca del viaje realizado por su diócesis anteriormente a su llegada, en el escrito describió en particular el territorio del sur entrerriano. ${ }^{[3]}$ Esto motivó a Vértiz a la creación de tres parroquias en 1780: Gualeguay, Gualeguaychú y Arroyo de la China (actual Concepción del Uruguay). Sin embargo, hubo desacuerdos con esta medida por parte de las latifundistas de Santa Fe opuestos a la creación de centros urbanos en Entre Ríos, debido a que la ganadería era una de los recursos que podía comerciar Santa Fe y La Bajada con el puerto de Buenos Aires, situación que generó disputas entre jurisdicciones, y desacuerdos entre los pobladores y la autoridad eclesiástica local.

En 1782 el virrey Vértiz envió a Tomás Juan Julián Marcos de Rocamora y del Castillo como comisionado a establecer poblaciones en la zona entre los ríos Paraná y Uruguay, donde habían ocurrido las disputas.

Rocamora envió varios informes sobre las posibilidades de la región, utilizando el término "Continente de Entre Ríos”, nombre que luego tomó la región. En los informes brindó datos sobre las 1.200 familias que habitaban la zona, de las buenas condiciones geográficas que alentaban al desarrollo de la ganadería, como también, de los conflictos que los pobladores mantenían con los terratenientes. En este sentido proponía la unificación de los partidos de Gauleguay, Gualeguaychú y Arroyo de la China, bajo un único comando.

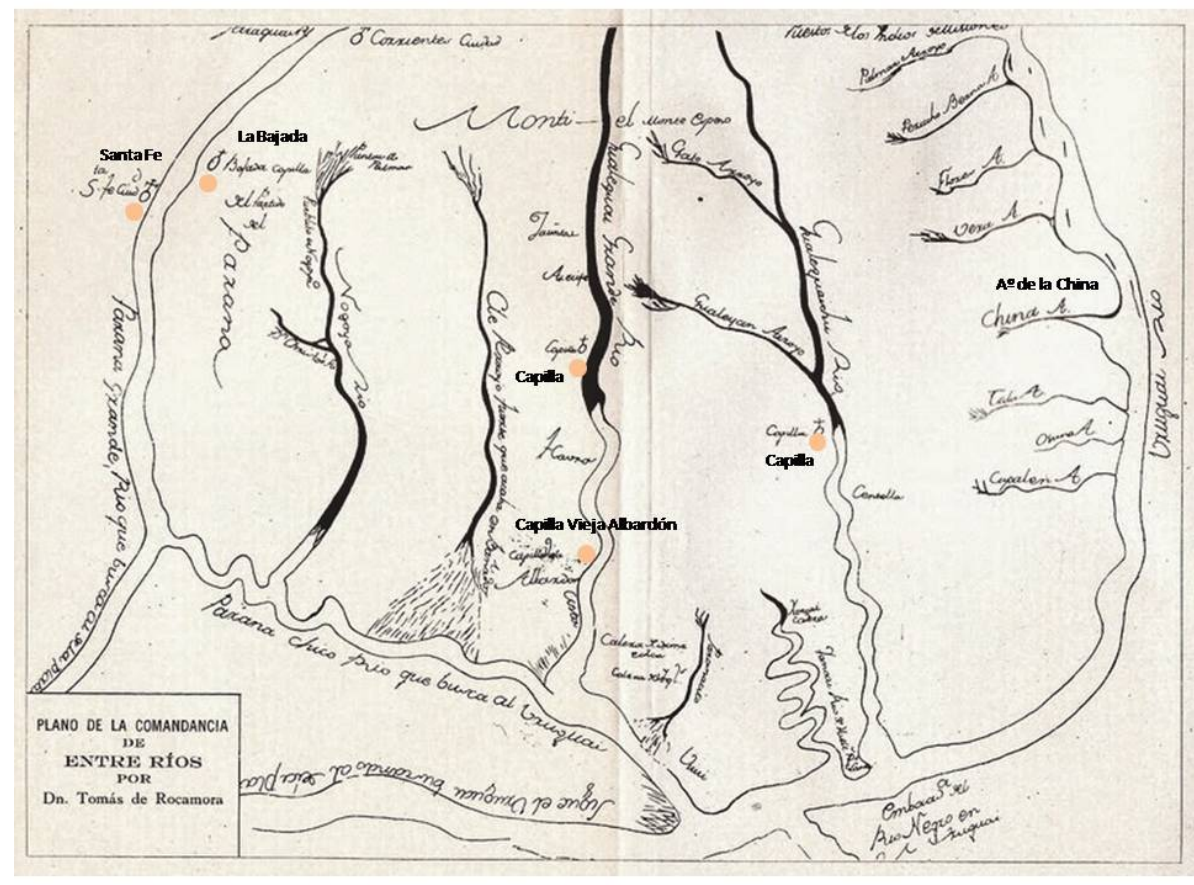

FIGURA 4

MAPA DE RELEVAMIENTO DE ROCAMORA.

FUENTE: ELABORACIÒN PROPIA SOBRE " PLANO DE LA COMANDANCIA DE ENTRE RÌOS", 1782, ROCAMORA. 


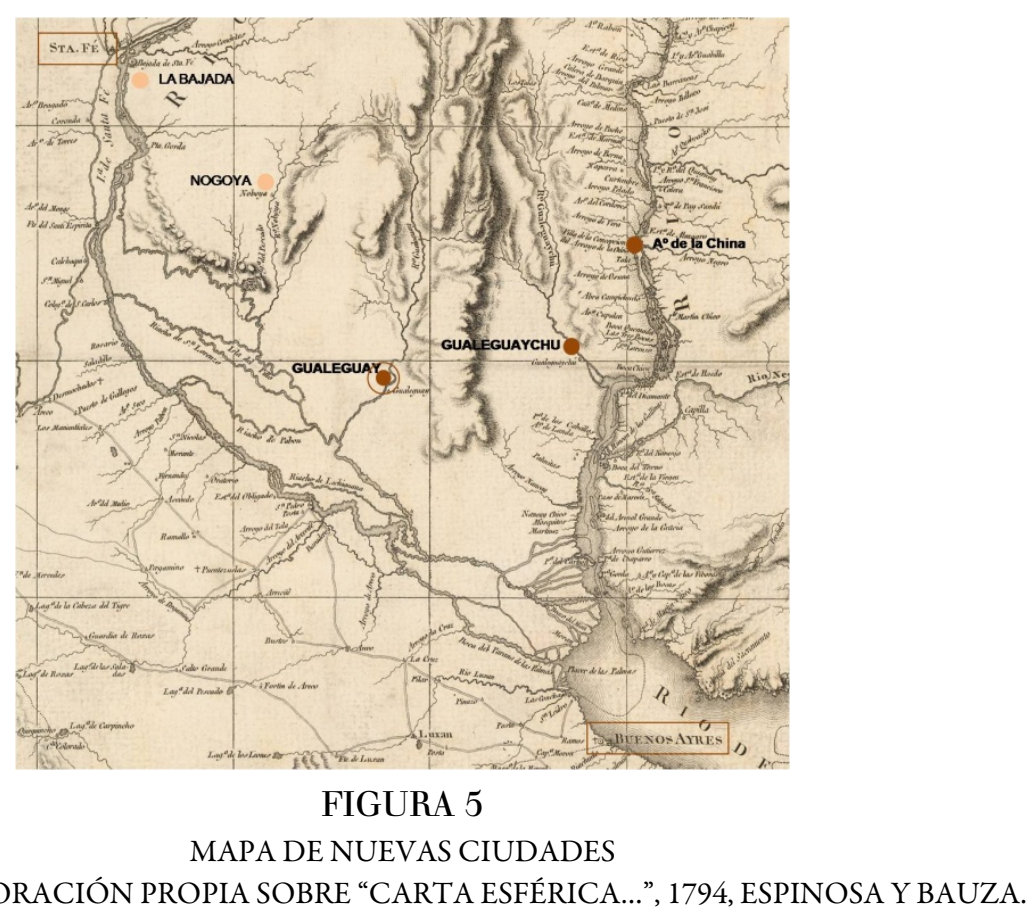

En septiembre del mismo año, Vértiz creó el cargo de Comandante General de Entre Ríos y nombró a Rocamora. De esta manera los Partidos de Gauleguay, Gualeguaychú y Arroyo de la China, sumados a Nogoyá y La Bajada, pasaron a jurisdicción de Buenos Aires con dependencia directa del Virrey.

En 1783, Rocamora fundó las villas de San Antonio de Gualeguay Grande, Arroyo de la China (Concepción del Uruguay) y San José de Gualeguaychú. Gestionó ante el Rey la categoría de «villa», otorgó instituciones y autoridades municipales, como los cabildos, y autorizó el faenamiento y exportación de cueros del ganado cimarrón.

Gualeguay fue fundada el 19 de febrero de 1783, bautizada como «Villa de San Antonio de Gualeguay Grande», en honor a su santo patrono, Antonio de Padua. ${ }^{[4]}$ Al momento de su fundación comprendía 56 manzanas y 150 vecinos que Rocamora reunió en el sitio que consideró adecuado junto al río Gualeguay. Dicho grupo estaba formado por familias de pequeños campesinos provenientes de La Bajada y establecidas junto a la Capilla Vieja en el Albardón del Arroyo Clé, (Figuras 4 y 5 ).

\section{El trazado}

Tomas de Rocamora (1740-1819) era nicaragüense, pero a muy temprana edad viajó a España donde se formó como militar. Participó en las Nuevas Poblaciones de Andalucía y consolidó su conocimiento en la gestión y en los aspectos técnico-políticos del plan urbano y territorial de las nuevas poblaciones, (De Paula, 2000).

En 1777 Rocamora participa en el desplazamiento de los portugueses del Rio de la Plata junto al virrey Pedro de Ceballos, y 1782 Vértiz le encomienda la misión a Entre Ríos.

En el momento de la fundación, Vértiz aconsejó a Rocamora proceder de acuerdo a las Leyes de Indias, pero este respondió que no contaba con esa documentación, pero si con la utilizada en las recientes fundaciones de Guadalupe (Canelones) y San Juan Bautista (Santa Lucía), en la Banda Oriental. Sin embargo, Rocamora desarrolló en Entre Ríos un diseño distinto a aquellos dos casos, aunque se infiere que utilizó su propia experiencia, como la desarrollada por otros contemporáneos en las nuevas fundaciones.

La demarcación de los trazados fue realizada por el Piloto de la Real Armada Pedro de Olmos, que consistió en una cuadrícula formada por ocho manzanas de lado, con calles de 10 varas $(8,4 \mathrm{~m})$ que rodeaban a 
manzanas de 80 varas $(70 \mathrm{~m})$ de lado. Más allá del amanzanamiento se previó un área para la futura expansión y dehesa de uso comunitario para el sustento cotidiano.

La plaza mayor ocupaba cuatro manzanas de 120 varas por lado, rodeada por una recova comercial (Figura 6 A.B,C) con ocho pabellones. Frente a la Plaza se debían establecer la Iglesia, la escuela, el cabildo y los edificios públicos (De Paula, 2000), y a su vez, del centro de la plaza se derivaban cuatro avenidas principales de 14 varas de ancho.

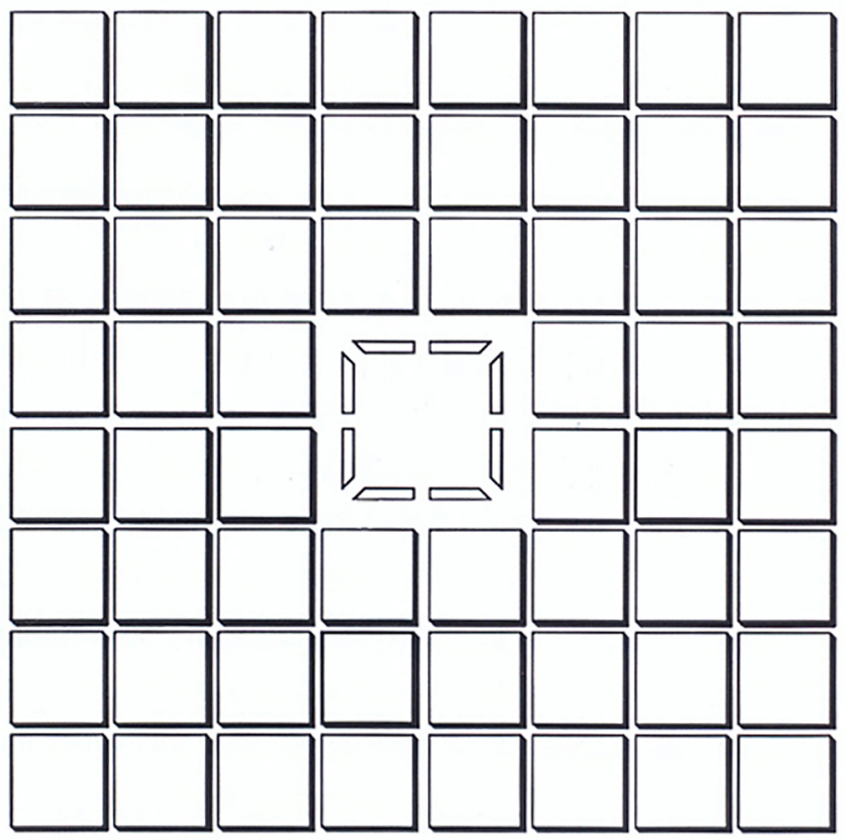

FIGURA 6A

A. ESQUEMA PLANTA URBANA DE GUALEGUAY. FUENTE: (DE PAULA, A., 2000). 


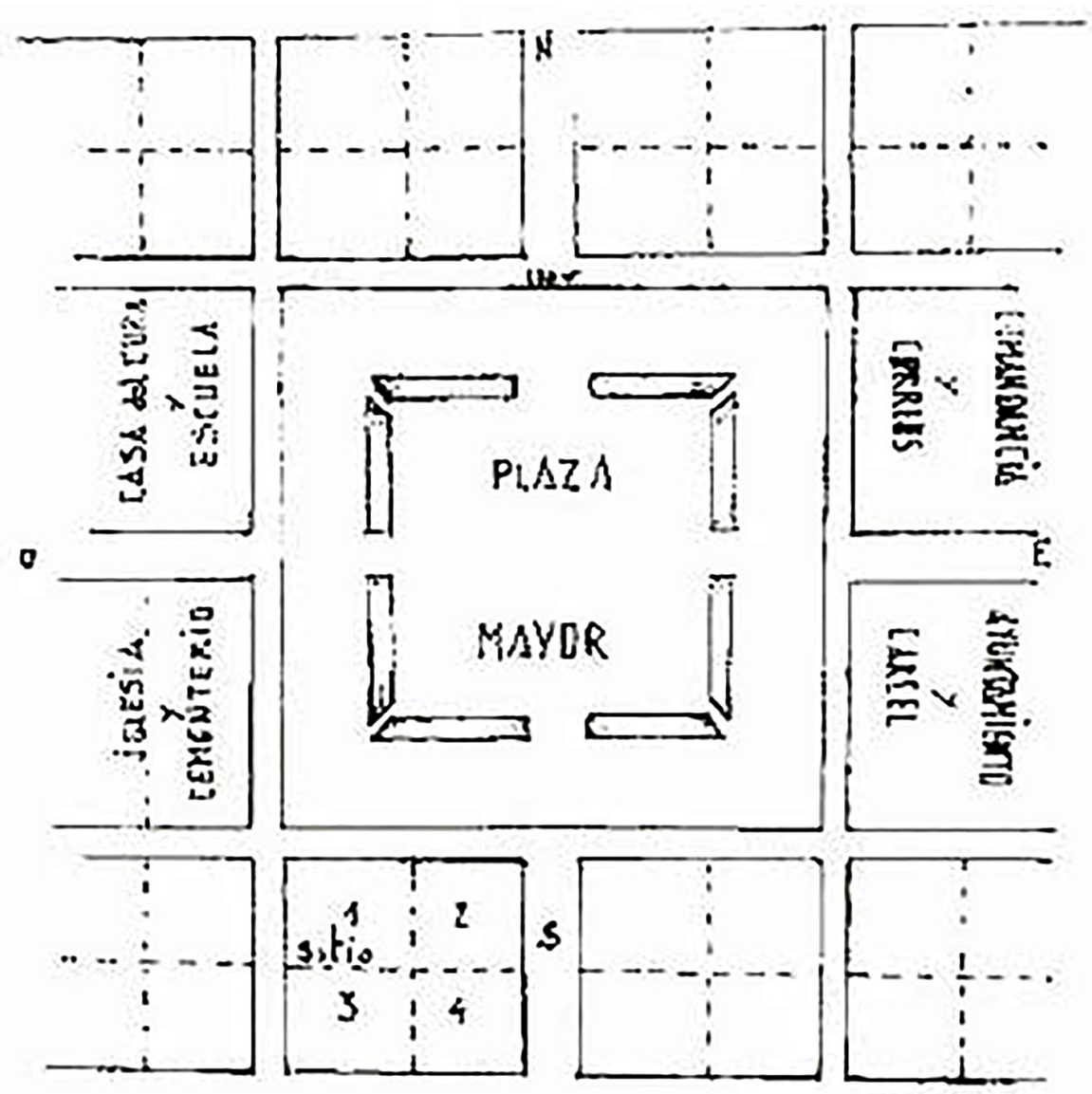

FIGURA 6B

B. ESQUEMA DE LA PLAZA MAYOR.

FUENTE: WIKIMEDIA COMMONS (25 NOVEMBER 2014). PLANO FUNDACIONAL GUALEGUAYCHU HTTPS://COMMONS.WIKIMEDIA.ORG/WIKI/FILE:PLANO_FUNDACIONAL_DE_GUALEGUAYCHU.JPG

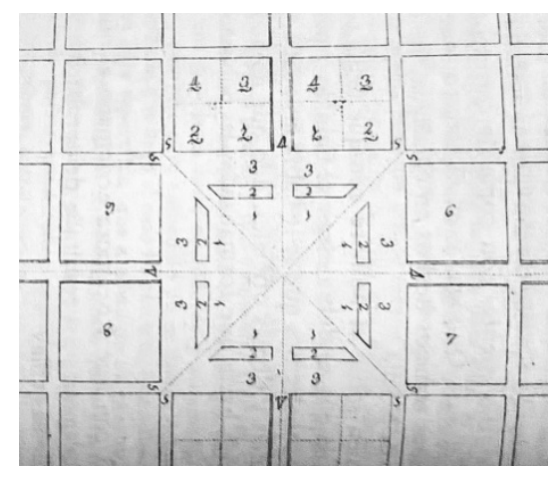

FIGURA 6C

Detalle Plaza Mayor: 1. Plaza, 2. Recova Comercial, 3. Calle Perimetral, 4. Calles principales, 5. Calles, 6. Comandancia y Correo, 7. Ayuntamiento y Cárcel, 8. Iglesia y Cementerio, 9. Casa Parroquial y Escuela. Manzanas de cuatro lotes FUENTE: (SEGURA, 1971).

En 1784 Vértiz es reemplazado por el Virrey Loreto, quien no continúo con el proyecto de las nuevas fundaciones y removió a Rocamora nombrando al terrateniente Francisco de Ormacchea.Si bien el proyecto no se concretó, la traza de Rocamora, a pesar de cierto desplazamiento, fue la base para la consolidación de la ciudad, (Figura 7). 


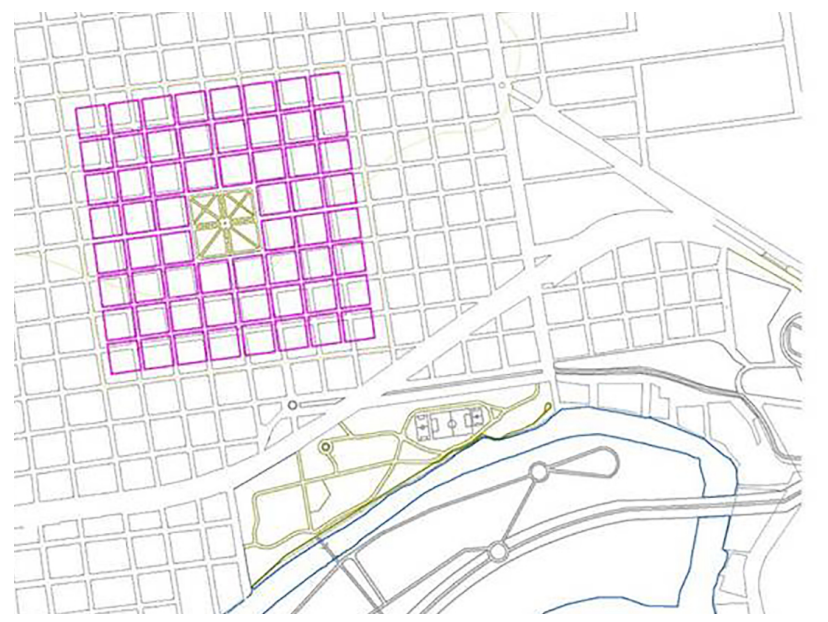

FIGURA 7

\section{REFERENCIAS}

CASCO FUNDACIONAL

RÍO GUALEGUAY

CUADRICULA ACTUAL

TRAMA ACTUAL Y FUNDACIONAL SUPERPUESTAS.

FUENTE: ELABORACIÓN PROPIA, DIBUJO DE DANIELA FERNÁNDEZ Y MAYRA RUGGIERO.

\section{CONFORMACIÓN DE LA ESTRUCTURA URBANA}

\section{GUALEGUAY Y SUS LÍMITES HISTÓRICOS.[5]}

Desde su fundación, la ciudad fue delimitada de hecho por las características naturales del enclave. Al sur y al este, la presencia del río Gualeguay y su llanura de inundación, marcaron los limites sobre dichos sectores, las curvas de $10 \mathrm{~m}$ y la de aproximadamente $5 \mathrm{~m}$ grafican con cierta precisión las escasas posibilidades de crecimiento en esa dirección, siendo testigos de esa condición las diferentes crecidas que avanzaron sobre dicho margen en varios momentos de la historia de la ciudad. Así mismo la diferenciación de las unidades geomorfologías, ya detalladas anteriormente en el subsistema natural, entre la llanura loéssica y la costa del río, confirman dicha delimitación.

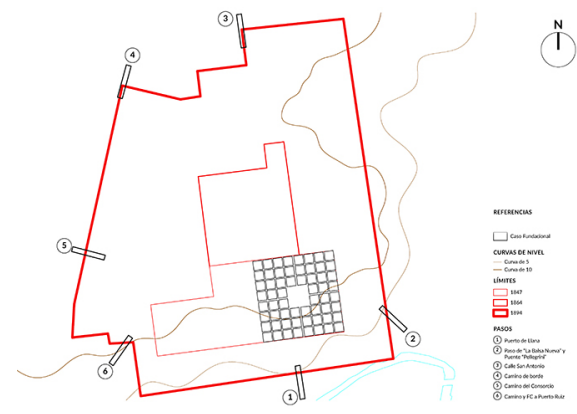

FIGURA 8

GRÁFICO SÍNTESIS, LÍMITES Y PASOS FUENTE: ELABORACIÓN PROPIA.

El rio era franqueado en algunos bajos por balsas, en particular el paso de la "Balsa Nueva" (2) que se vinculaba con el camino a Gualeguaychú y próximo al muelle del "Puerto de la Llana" (1). Para 1898 se construyó el primer puente de madera proyectado por el Ing. Carlos Cassaffousth, pero afectado por varias crecidas se reconstruyó con hierro y madera, con una longitud de $400 \mathrm{~m}$, e inaugurándose en 1907 bajo el nombre de "Pellegrini". Debido a las fuertes bajantes del río el puerto propio no prosperó, dependiendo entonces del Puerto Ruiz, que fue creado en 1837 a $10 \mathrm{~km}$ al sur de la misma, convirtiéndose el camino a dicho puerto y al que se le sumo el ferrocarril en 1866, en otro paso del límite sur (6). 
El límite de la mancha urbana hacia el Oeste se fue desplazando en el tiempo sobre las zonas de quintas, un primer avance al suroeste, se debió al traslado del cementerio, y a la construcción de la "Capilla de la Sagrada Familia" en 1847. En 1877 se construyó la "Plaza Rocamora”, frente a la Capilla y al acceso al Cementerio. También la calle Suipacha, eje central del damero fundacional, y por donde arribó el primer ferrocarril a Puerto Ruiz en 1866, actuó como eje de expansión del área central al oeste, encontrando su límite en la zona de quintas y chacras, que la delimitación del Ejido de 1875, y el tendido del ferrocarril a Tala en 1888, consolidó. Si bien el mapa de 1894 muestra el proyecto de cuatro bulevares, como límites de la ciudad futura, y paralelos a la plaza central, el bulevar oeste fue el único que no se concretó y el camino de borde paralelo al ferrocarril, oficio como tal, el camino rural a Punta del Monte con paso a nivel, denominado "Camino del Consorcio" (5), fue el paso del límite oeste.

El límite norte se materializó en base a la traza del proyecto del Boulevard Norte, y a los límites del ejido. El primer avance de la expansión al norte fue la construcción de la Capilla San José y de la Plaza Nueva, en 1864, afirmando el eje de la calle San Antonio y reforzado por la construcción del Hospital San Antonio en 1904 junto al Boulevard norte. Los pasos del límite Norte fueron fundamentalmente, la continuación de la calle San Antonio en las rutas al norte (3), y el propio camino del borde oeste (4).

Los límites de la ciudad de Gualeguay se conformaron a partir, de una combinación entre las condiciones geográficas y la geometría del trazado fundacional, luego tres de sus lados se mantuvieron ortogonales, paralelos entre sí, y el cuarto se ajustó a la traza del Ejido y del ferrocarril a Tala.

\section{Caminos. La Red de Vinculación en el GualeguaY de Fin de Siglo.[6]}

Las conexiones en la región, previas a la fundación de Gualeguay, eran casi inexistentes para los colonizadores, seguramente los indígenas poseían su red de caminos y navegación, pero estos no fueron registrados en los mapas consultados. Con la fundación de los tres enclaves del Virreinato en el sureste de Entre Ríos, Rocamora establece caminos entre estos, y los vincula con Nogoyá y la Bajada (Paraná), hacia el Noroeste. De esta manera, hasta la mitad del siglo XIX, existían principalmente tres orientaciones que vinculan a Gualeguay. Hacia el este, con Gualeguaychú y el río Uruguay, hacia el noroeste, con Nogoyá y La Bajada, (Figura 9), y hacia el sur, la conexión con Puerto Ruiz. La conexión sur marca la importancia capital que tuvo la vía fluvial para el desarrollo de la ciudad, tanto por facilitar el transporte de cargas, como la comunicación con los centros urbanos. Cabe señalar, que las condiciones geográficas, relieve y zonas inundables, y el escaso desarrollo de la infraestructura de caminos, presentaban grandes desventajas para el transporte terrestre.

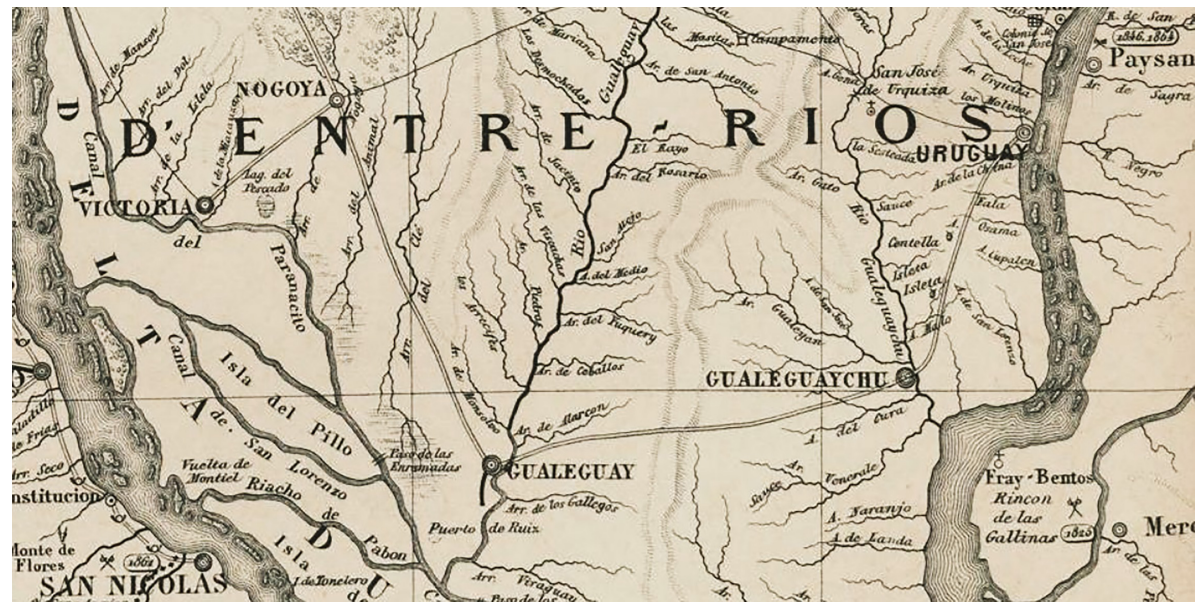

FIGURA 9

DETALLE DE LA “CARTA DE LA PROVINCIA DE ENTRE RÍOS...”, 1865

FUENTE: MOUSSY. 


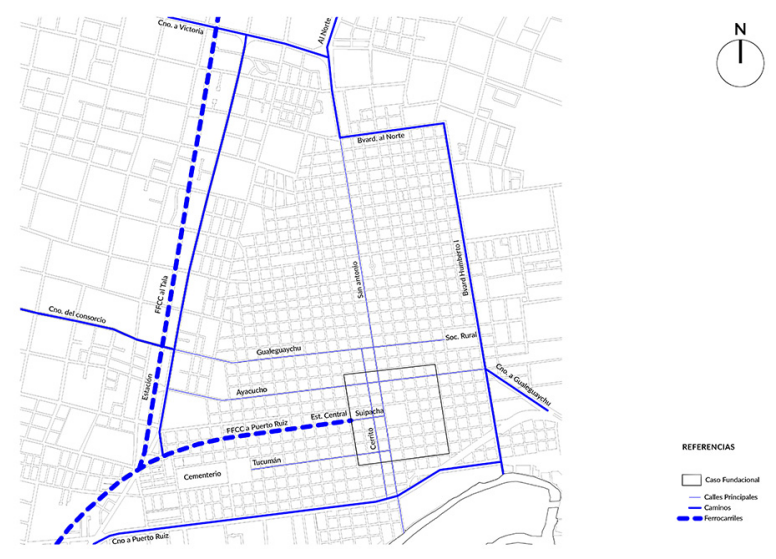

FIGURA 10

GRÁFICO SÍNTESIS CAMINOS

FUENTE: ELABORACIÓN PROPIA, DIBUJO DE DANIELA FERNÁNDEZ Y MAYRA RUGGIERO.

Durante varias décadas de la segunda mitad del siglo XIX Puerto Ruiz desarrolló una intensa actividad. Tanto los buques de carga como de pasajeros cubrían trayectos entre Gualeguay y Montevideo o Buenos Aires, o hacia el norte itinerarios a Santa Fe, Rosario, Victoria y Paraguay. En 1866 la conexión con Puerto Ruiz se incrementó gracias a la construcción, por parte de capitales privados, del "Primer Ferrocarril Entrerriano", permitiendo la vinculación entre las dársenas del puerto y 1 casco fundacional. ${ }^{[7]}$ La producción ganadera era la de mayor envergadura comercial, encabezando las exportaciones, en cambio las importaciones, correspondían a productos industrializados.

Por otra parte, existía una vinculación directa entre el Puerto de los Llanos y el eje central de la calle San Antonio, calle lateral de la plaza principal y de la iglesia San Antonio.

El arribo a la ciudad por el este desde Gualeguaychú, dependía del cruce con balsas del río Gualeguay, y luego de 1898, por medio del Puente Pellegrini conectando con el Boulevard este (Humberto I), y con el casco fundacional por la calle Ayacucho.

Desde el oeste el "Camino de Consorcio" comunicaba la zona de quintas y chacras con el área central por intermedio de la calle Gualeguaychú.

Una cuarta dirección, de menor importancia en un primer momento, fue el camino en dirección norte hacia Tala. Luego de 1880, se conectaban cuatro caminos, uno con dirección a Victoria, otro hacia Nogoyá, un tercero hacia el centro norte, y un último, casi paralelo al río Gualeguay, hacia Tala. Todos estos caminos se unían en las afueras de la ciudad y entraban en la misma por su arteria principal, la calle San Antonio.

En 1885 se inician las obras de la Ferrocarril Central Entrerriano que vinculaba Paraná con Concepción del Uruguay, en un primer momento este ramal no incluía a Gualeguay, pero en 1888 se conectó dicha ciudad, incluyendo el tramo a Puerto Ruiz. El ramal se trazó al oeste de la ciudad, reforzando el límite, y se localizó la nueva estación en la intersección de la calle Ayacucho, siendo la vieja estación desmantelada en 1926.

Las principales calles internas se vinculaban con las salidas externas, conectando a estas con los nodos, hitos y áreas relevantes, durante el período en estudio. En el sentido norte-sur eran las calles San Antonio, que vincula las dos plazas, la calle Cerrito, segunda arteria de importancia en el área central, y en los límites, el Boulevard Humberto I y la calle junto al Ferrocarril. En el sentido este-oeste se distinguen la calle Tucumán que conectaba con la Plaza Rocamora, el Cementerio y la Capilla, la calle Suipacha enlace con la vieja estación y camino a Puerto Ruiz, la calle Ayacucho que vinculaba el casco fundacional con la nueva estación, la calle Gualeguaychú que ligaba el "Camino del Consorcio" con el predio Ferial de la Sociedad Rural, y en los límites, los Bulevares norte y sur.

Nodos en la estructura urbana de Gualeguay. ${ }^{[8]}$ 


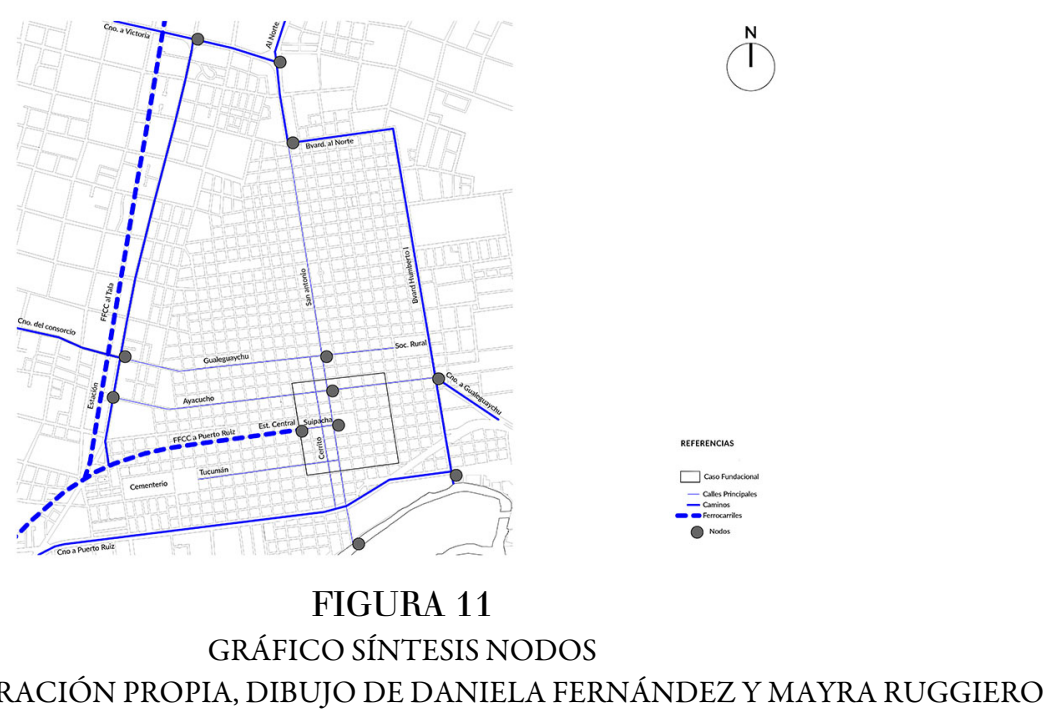

En el sector norte de la ciudad se concentraban tres nodos que actuaban en la entrada y salida de la ciudad hacia el noroeste y centro de la provincia, con especial vinculación con la ciudad de Paraná, capital de la provincia. Estos nodos reforzaban las calles internas San Antonio y el camino de borde.

En el sur, el puente Pellegrini articulaba la conexión con el camino a Gualeguaychú y al río Uruguay, y el Boulevard Humberto I y Sur. El Puerto de los Llanos vinculaba la vía fluvial con la calle San Antonio, y más al sur el Puerto Ruiz con las vías fluviales centrales hacia Buenos Aires, Montevideo y Rosario, entre otras ciudades.

Los nodos hacia el oeste eran, la Estación Central del Ferrocarril a Puerto Ruiz en la intersección de las calles Suipacha y Buenos Aires, hasta su desaparición, y luego el nodo de la estación del Ferrocarril a Tala y la calle Ayacucho, que unía con el centro de la ciudad y el Boulevard Humberto I. Por otra parte, se encontraba el nodo de la intersección del Camino del Consorcio con la calle del Ferrocarril y la calle Gualeguaychú.

En el interior de la ciudad se destacaban como nodos significativos, las uniones entre el eje central (calle San Antonio) y las calles Gualeguaychú, Ayacucho y Suipacha, ya mencionadas.

\section{LOS HITOS DE LA CIUDAD.9}

En el proceso de consolidación de la estructura urbana de la ciudad de Gualeguay encontramos varias etapas diferenciadas que se relacionan con los cambios políticos y socio-económicos. Un primer período comprende la etapa de los pueblos originarios y fundacional, que ya hemos tratado, una segunda fase que abarca desde el fin del siglo XVIII hasta mediados del siglo XIX, caracterizada por las idas y contramarchas generadas por el fin del periodo colonial y la gestación de la nueva república, una tercera etapa en donde se fortalecen ciertos fragmentos urbanos y se generan nuevos elementos estructurales, y un cuarto período que predomina la consolidación de la ciudad de comienzos del siglo XX.

En este proceso surgen numerosos espacios que albergan diversas actividades - tanto en espacios interiores como exteriores de la ciudad - imbuidos de una gran carga simbólica que es generada, mantenida e identificada por los distintos sectores sociales de la ciudad, y a los que identificamos como hitos urbanos. 


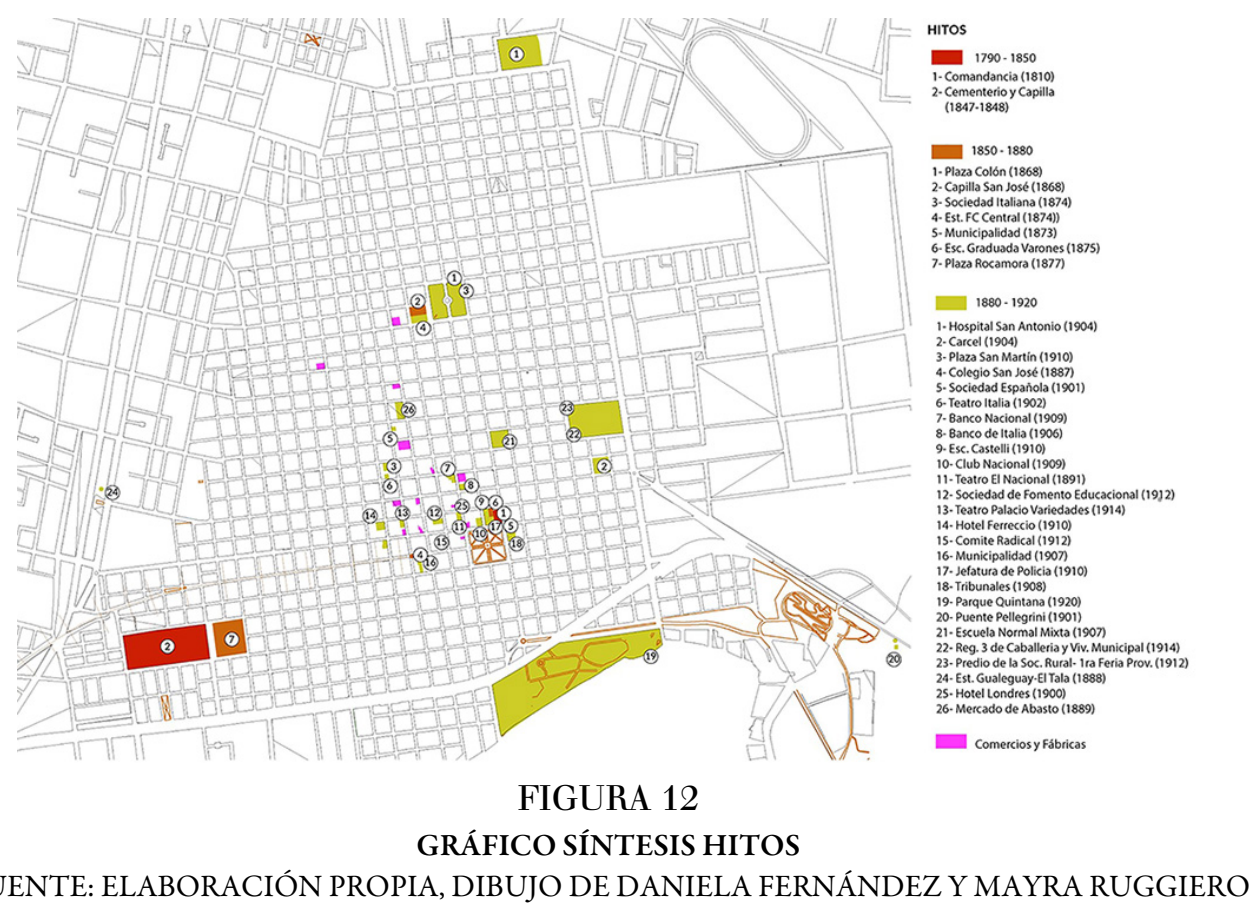

\section{ETAPA 1790 - 1855}

Uno de los primeros espacios que definió la ciudad fue el conjunto de Plaza, Iglesia y Comandancia. Rocamora en la fundación había destinado el predio de la esquina NE a cárcel y cuartel. Ya 1810 era ocupado por la Comandancia y la cárcel, era una construcción de adobe y cubierta de tirantes con cumbrera de palma -en dicho sitio fue encarcelado y torturado Giuseppe Garibaldi en 1837. Para 1847 se construyó un edificio de material que fue asiento de la Municipalidad en 1873.

En el centro de la Plaza en 1851, los vecinos de la ciudad decidieron levantar una columna conmemorativa al "Pronunciamiento" del Gral. Justo José de Urquiza contra Rosas. En agradecimiento a dicho homenaje Urquiza envió un copón de mármol que fue ubicado en lo alto de la columna. ${ }^{[10]}$

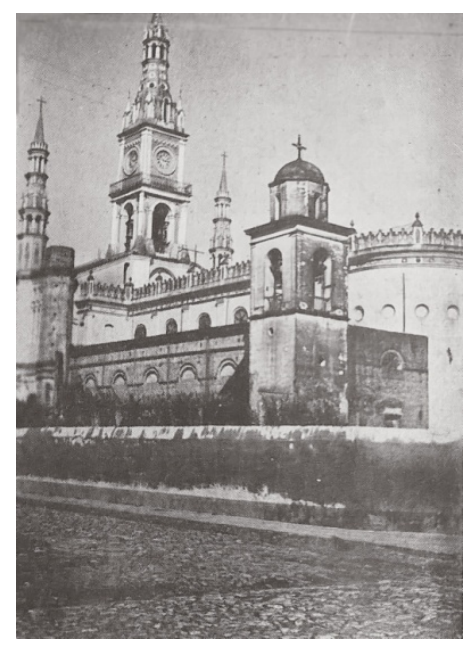

FIGURA 13

FRAGMENTOS DE LA CAPILLA ANTIGUA E IGLESIA DE SAN ANTONIO, 1903.

FUENTE: DIARIO “EL SUPREMO”, EDICIÓN DEL BICENTENARIO DE LA FUNDACIÓN DE GAULEGUAY 


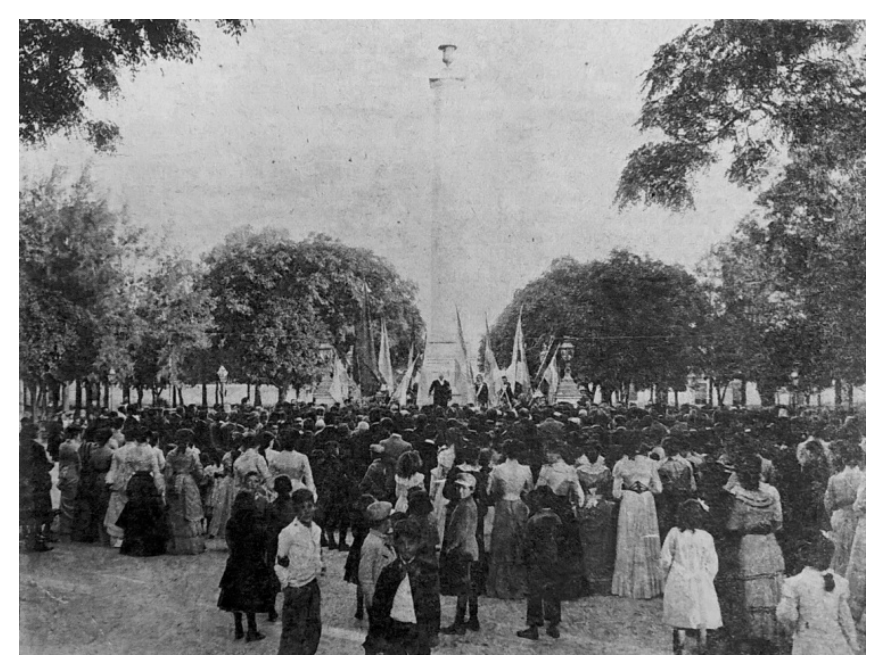

FIGURA 14

ACTO EN PLAZA CONSTITUCIÓN JUNTO A LA COLUMNA Y COPÓN OBSEQUIADO POR URQUIZA (CIRCA 1890). FUENTE: DIARIO “EL SUPREMO”, EDICIÓN DEL BICENTENARIO DE LA FUNDACIÓN DE GAULEGUAY

El desarrollo del casco fundacional obligó a trasladar el Cementerio hacia las afueras de la ciudad en dirección al oeste. En 1847, con aportes del Gobernador Gral. Urquiza, se construyó la nueva necrópolis y junto a su acceso, la Capilla de la Sagrada Familia.

\section{ETAPA 1855 - 1880[11]}

La aparición del Ferrocarril Primer Entrerriano que conectó a la ciudad con Puerto Ruiz en 1866 - uno de los primeros ferrocarriles del país - generó un andén terminal en la esquina de las calles Suipacha y Buenos Aires. En la construcción del ramal ferroviario participaron numerosos obreros inmigrantes italianos.

En 1868 se inauguró la Capilla San José, en el extremo norte de la ciudad sobre la continuación de la calle San Antonio, en una zona aún poco ocupada.Al mismo tiempo se decidió establecer una plaza frente la capilla denominándola Plaza San José, luego Colón. De esta manera se configuró un nuevo polo de atracción que consolidó el eje principal de la calle San Antonio y la expansión de la ciudad hacia el norte.

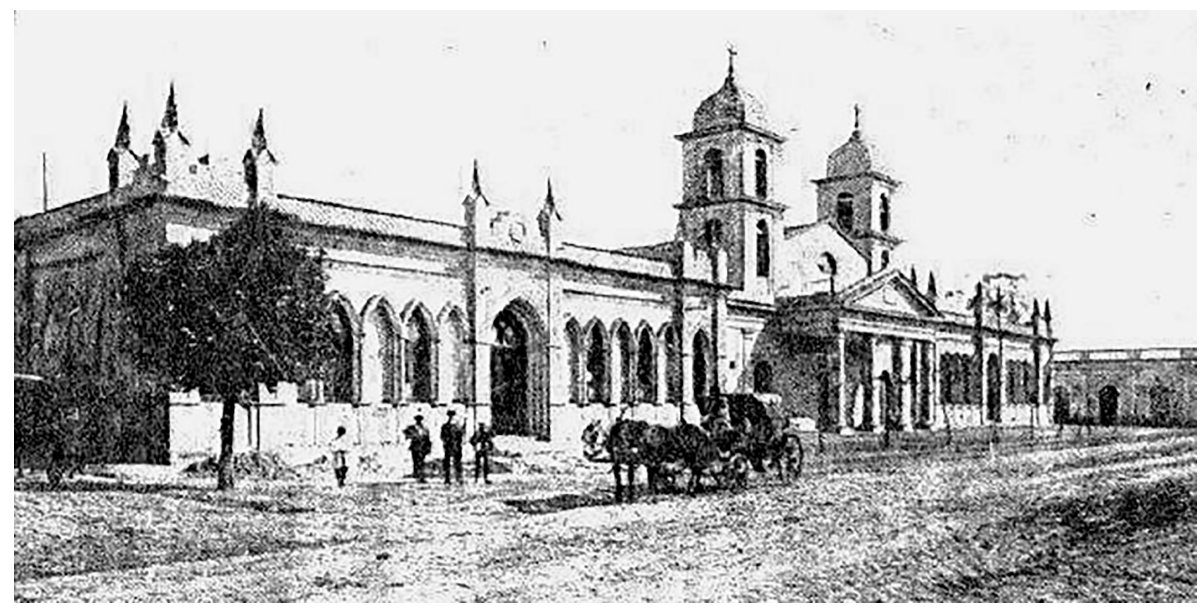

FIGURA 15

CAPILLA SAN JOSÉ, ASILO Y ESCUELA SAN JOSÉ, Y SOCIEDAD ITALIA, FACHADA CALLE ISLAS MALVINAS. FUENTE: POSTAL ED. ANTUNEZ\&CIA. HTTPS://FILATELIAARGUELLO.COM/ES/GUALEGUAY 


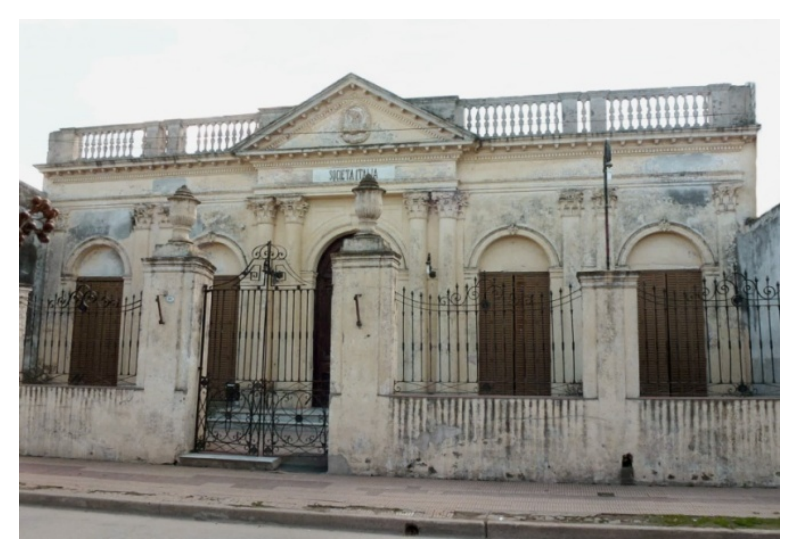

\section{FIGURA 16}

SOCIEDAD ITALIA, FACHADA CALLE ISLAS MALVINAS

FUENTE: HTTPS://WWW.TURISMOENTRERIOS.COM/GUALEGUAY

También ese mismo año se creó la Sociedad Italia de Socorros Mutuos, inaugurando su edificio en 1874. La Municipalidad se estableció frente a la plaza en 1873, y en 1875, en la misma manzana, se construyó la Escuela Graduada de varones. Enfatizando al edificio de la municipalidad como hito urbano, en 1877 se colocó el primer reloj público en la torre de la Municipalidad construida por la firma italiana Antola y Cía.

\section{ETAPA $1880-1920$}

Para 1876 la Municipalidad llamó a licitación para la construcción de un Mercado de Abasto en la calle Sarmiento, a mitad de camino entre las dos plazas.

El 23 de noviembre de 1890 arribó el primer tren a la Estación del Ferrocarril Gualeguay-Tala, hecho que conectó a la ciudad con el principal ramal de la Provincia. La aparición de la estación consolidó el crecimiento de la ciudad al oeste, con eje en la calle Ayacucho, hecho que se reforzó a partir de 1907 cuando se conectó dicho ramal ferroviario con el Puerto de Ibicuy y el Ferry-Boat a Zárate-Buenos Aires.

Sin bien existía el "Teatro Rocamora”, la aparición del Teatro "El Nacional” en 1891, fue un gran acontecimiento para la ciudad. El proyecto fue realizado en Buenos Aires y contemplaba una capacidad para 700 localidades. Una cooperadora de vecinos inversores formada con ese fin, controló la construcción, para la que se importaron los mármoles y balaustre para palcos y cazuelas, que arribaron en el Vapor "Indio" (Figura 17) y (Figura 18). 


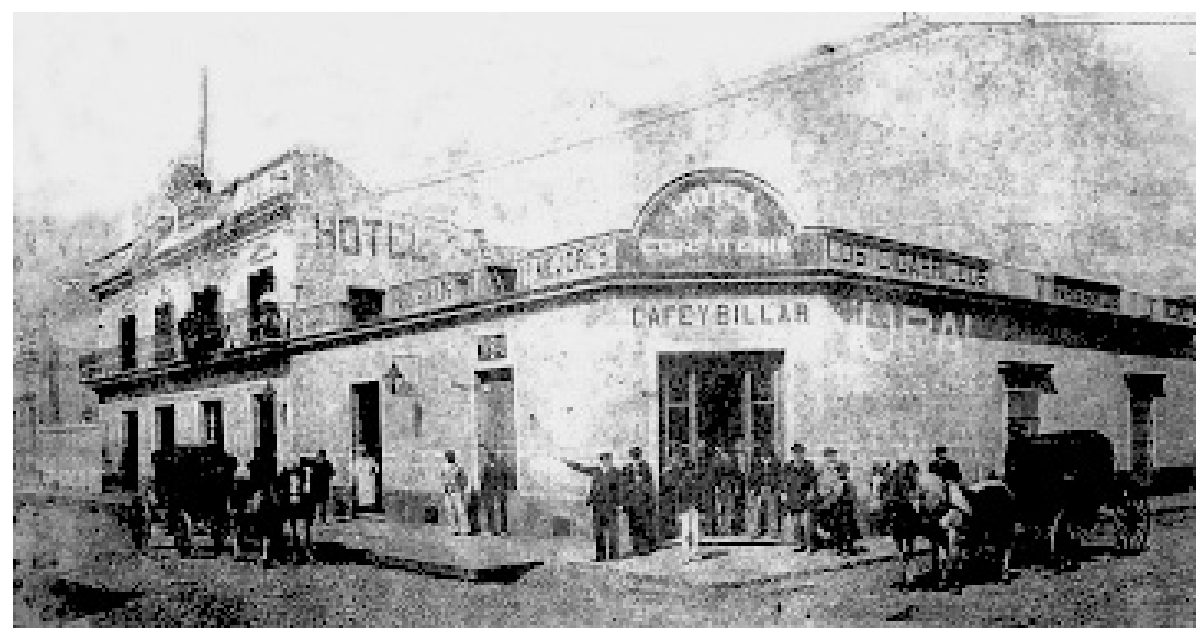

FIGURA 17

FACHADA DEL TEATRO NACIONAL, A LA IZQUIERDA, SOBRE CALLE SAN ANTONIO. FUENTE: "GUALEGUAY DE BOLSILLO", N. RAMPOLDI.

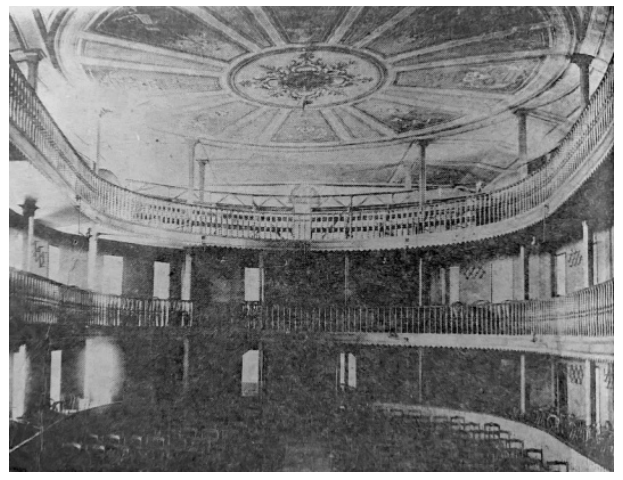

FIGURA 18

SALA PRINCIPAL DEL TEATRO

FUENTE: DIARIO “EL SUPREMO”, EDICIÓN DEL BICENTENARIO DE LA FUNDACIÓN DE GUALEGUAY.

En el teatro actuaron numerosos elencos como la "Compañía de Operas Italianas" y se realizaron significativos encuentros vecinales y políticos, como también, la proyección de películas, pero lamentablemente en 1910 un incendio destruyó sus instalaciones.

En 1902 la Sociedad Italia de Socorros Mutuos inauguró el Teatro Italia (Figura 19) y (Figura 20). Desde un primer momento fue un centro de varias actividades culturales y sociales, pero adquirió mayor relevancia luego del incendio del Teatro Nacional. 


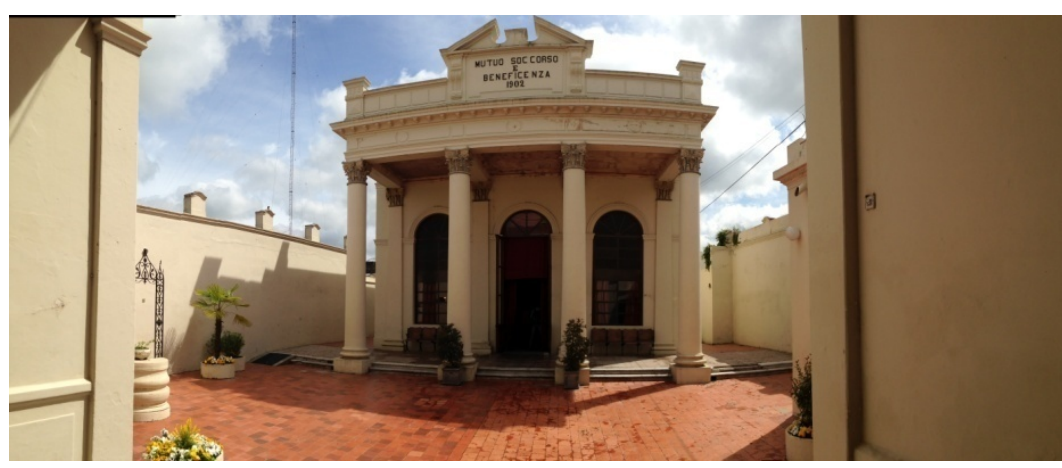

FIGURA 19

FACHADA DEL TEATRO ITALIA (FOTO ACTUAL)

FUENTE: FOTOGRAFÍA ARQ. M. CAPELUTO

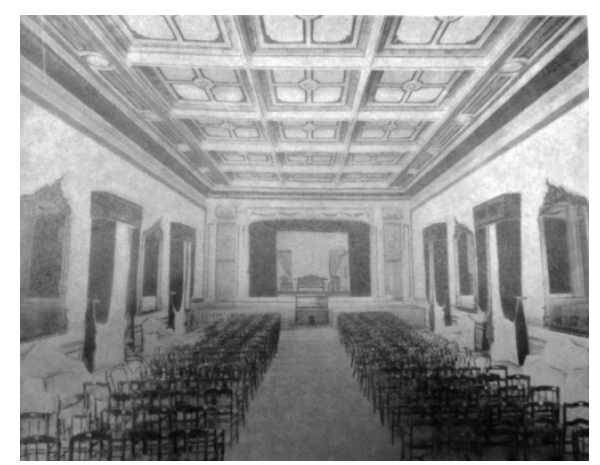

FIGURA 20

SALA PRINCIPAL DEL TEATRO (CIRCA 1902).

FUENTE: ARCHIVO DEL TEATRO ITALIA

Siendo las elecciones en Santa Fe el 31 de Marzo de 1912, la crónica narra:

"A última hora de aquel día, el telégrafo anunció el resultado de la elección y si bien aún no se conocían los cómputos finales, era casi segura la victoria radical....Alrededor de las 20,30 horas y cuando ya era noche cerrada, la masa radical gualeguayense salió a la calle, reuniéndose sin distinción, hombres y mujeres y organizando una manifestación clamorosa que inició su marcha por calle San Antonio hasta el domicilio del Dr. Celestino Marcó,...El Dr. Marcó se incorporó a la bulliciosa columna cívica, que tomó camino hacia el Teatro Italia, colmando su salón y ocupando el amplio patio; todos los palcos se vieron bien pronto repletos, destacándose en ellos la presencia femenina, luciendo las damas la insignia partidaria y arrojando una verdadera lluvia de flores al paso de los dirigentes hacia el escenario...La gente que llenaba el Teatro volvió a la calle y organizándose nuevamente en manifestación se dirigió hasta la Plaza Constitución," (Vico, 1972).

Como resultado de la gestión de la Sociedad de Beneficencia y la Iglesia local, se obtuvo de la Municipalidad la donación de terrenos en el límite norte para la construcción del Hospital San Antonio, este fue inaugurado en 1904 sobre la base del proyecto realizado por el Arq. Juan Buschiazzo.

A partir de 1900 en varias esquinas del área central se establecieron hoteles y confiterías, como el "Londres", o el "Genovés", identificados por los habitantes como espacio de acontecimientos sociales, junto a numerosos comercios, fábricas y talleres localizados en la calle San Antonio, y cercanos a la Plaza Constitución.

Al finalizar la primera década del siglo XX, Gualeguay tuvo un importante desarrollo en la construcción de edificios educativos. La Escuela Superior Graduada Mixta en 1907, y la Escuela Juan José Castelli en 1912. Ambas escuelas fueron en ese momento uno de los edificios de mayor impacto visual en la ciudad.

Con conexiones con bancos europeos, y en especial con bancos de Italia, se inauguró en 1906 el Banco de Italia y Río de la Plata, en la esquina de Ayacucho y San Antonio, y en 1909 el Banco Nación, construyó una nueva sucursal a cargo del arquitecto italiano Salvador Mirate, en la esquina de las calles San Antonio y Uruguay. 
Luego de la reforma constitucional de la Provincia de Entre Ríos en 1903, y las Leyes Orgánica Judicial y Carcelaria de 1904, se decidió la construcción del Palacio de Tribunales frente a la Plaza Constitución, y la construcción de la Cárcel en los límites de la ciudad.

El 7 de Julio de 1907 se colocó una placa recordatoria del centenario del nacimiento de Giuseppe Garibaldi en la esquina de Ayacucho y San Antonio. La colectividad italiana junto a otras colectividades, rindieron homenaje en la Sociedad Italiana y en el frente de la casa del Dr. Andreu - lugar donde se hospedó Garibaldi en su paso por Gualeguay. Junto al hito conmemorativo, se dispuso el poste cumbrera de donde fuera colgado y torturado el héroe italiano. Dicho monumento se convirtió en un hito significativo de la historia de la colectividad y de la ciudad.

En 1910 se decide demoler el edificio que albergó a la Municipalidad y construir el nuevo edificio de la Jefatura de la Policía, quedando habilitado en 1912, mientras la Municipalidad se traslada a la mansión de Juan Bautista Chichizola - inmigrante, destacado comerciante dueño del comercio "La Proveedora", y activo participante de la vida pública de la ciudad - a metros de la plaza principal.

También otros hitos destacados de la ciudad se encontraban dentro del área central, como la Sociedad Española de Socorros Mutuos Rocamora, el Club Social frente a la Plaza Constitución, o en sus límites, la Sociedad Rural, encargada de realizar la Gran Feria y Exposición Provincial, en donde luego se instaló el Regimiento 3 de Caballería.

\section{ÁMBITOS, EL CENTRO CONSOLIDADO[12]}

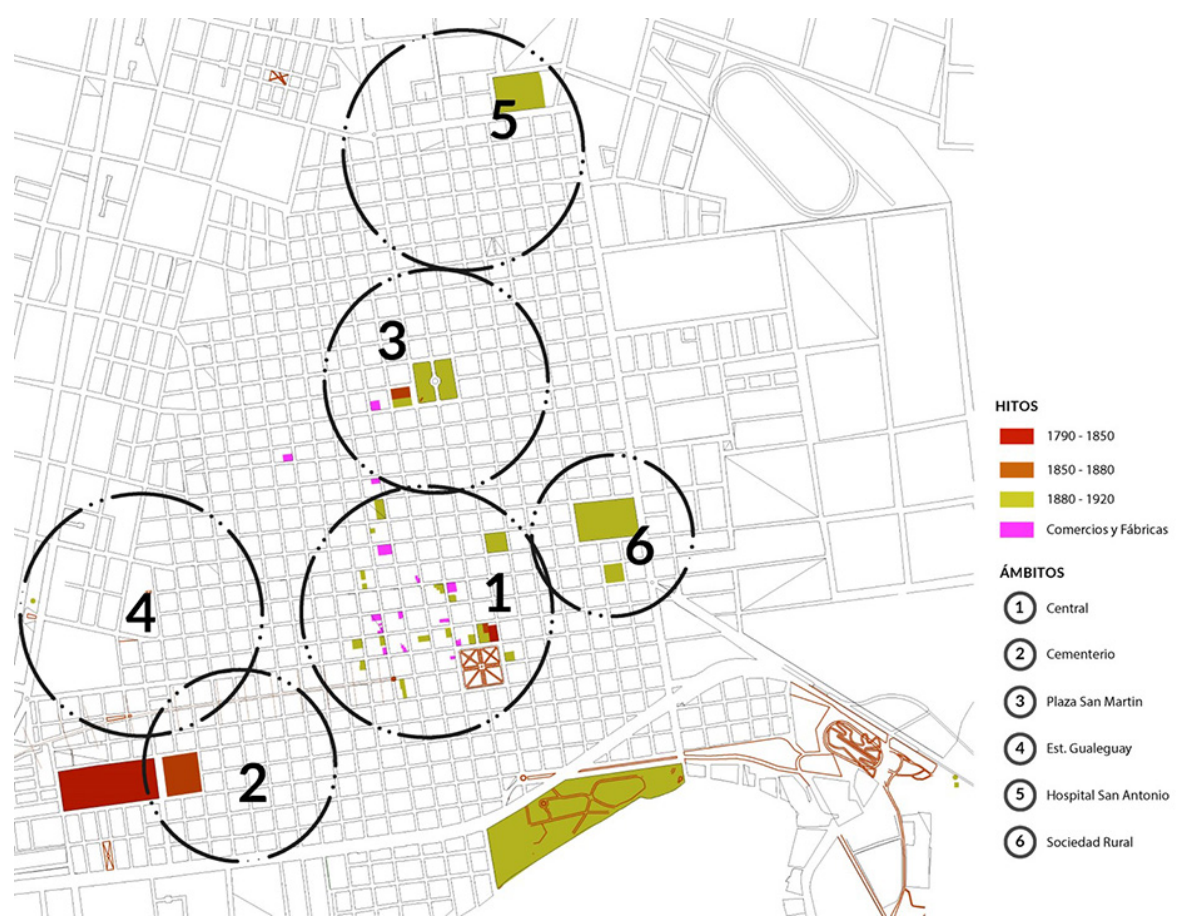

FIGURA 21

GRÁFICO SÍNTESIS ÁMBITOS

FUENTE: ELABORACIÓN PROPIA, DIBUJO DE DANIELA FERNÁNDEZ Y MAYRA RUGGIERO.

En el periodo tratado, se puede constatar la consolidación del área central como el "barrio céntrico", y algunos sectores que van formando su propia identidad dentro de la ciudad.

Hasta 1860 los terrenos urbanos de 34 x 34 m., y los suburbanos (chacras) de 300 x $300 \mathrm{~m}$. se otorgaban en forma gratuita a condición de cercarlos y ocuparlos. 
Cuando Rocamora en 1783 estableció la traza de lo que luego sería el casco fundacional, no delimitó el ejido, quedando sin definir hasta 1876 cuando el Departamento Topográfico de la Provincia de Entre Ríos lo aprobó y la Municipalidad puso en venta los terrenos. Para ese entonces el valor de un terreno urbano era de 100 pesos y una chacra de 150 pesos, mientras que en 1912 un lote en el área central costaba 4.000 pesos, en la periferia 300 pesos, y las chacras sin vivienda 1.300 pesos. (Vico,1972)

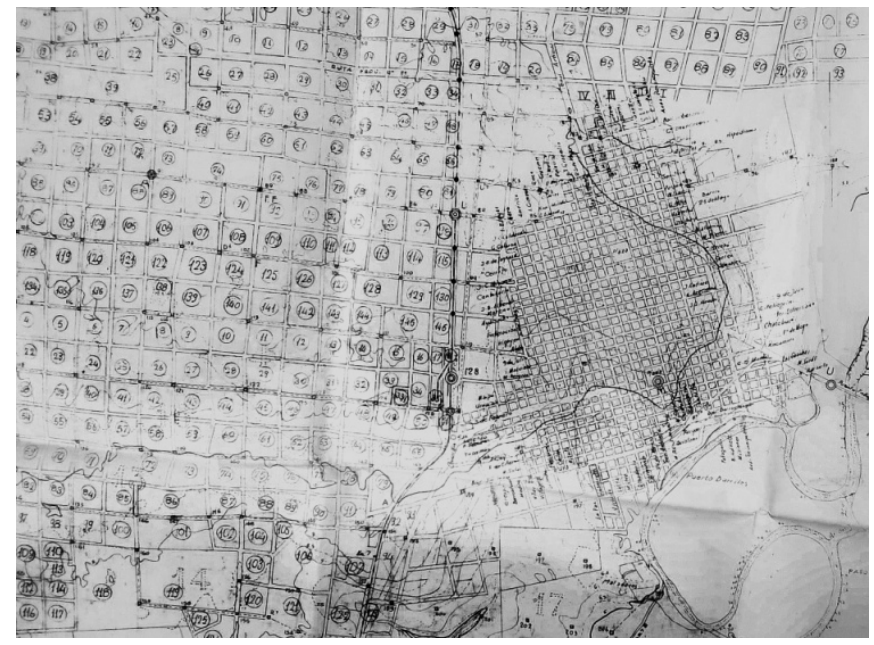

FIGURA 22

FRAGMENTO DEL “PLANO DE NIVELACIÓN Y PLANIMETRÍA. EJIDO DE GAULEGUAY”

FUENTE: EN BASE AL PLANO DE 1924 DPI- 1968. CONSULTADO EN EL MUSEO MUNICIPAL

Luego de la delimitación del ejido, en el transcurso de 36 años, y coincidiendo con el periodo de mayor crecimiento integral de la localidad, el valor de la tierra aumentó notablemente definiendo áreas diferenciadas: área rural, área periférica y área central. A su vez se incrementó la población, tanto del ejido, como la correspondiente al Departamento, siendo la del ejido un $75 \%$ mayor para 1914 . $^{[13]}$

Para 1888 llegaban inmigrantes desde Buenos Aires a Puerto Ruiz, fundamentalmente italianos y españoles, quienes se instalaban próximos a sus parientes o conocidos, llegados anteriormente.

La proximidad de ciertas actividades relacionadas con la administración pública, el trabajo, el comercio o la recreación, como también las vías jerarquizadas, los nodos y las infraestructuras, ayudaron a consolidar el área central, dejando los alrededores vinculados a ciertos hitos principales.

En una primera aproximación, se pueden detectar los siguientes ámbitos:

1. Central: Consolidado a partir del casco fundacional (Plaza Constitución) y se expande hacia el noroeste, con eje en la calle San Antonio, enfatizado por las calles Ayacucho y Gualeguaychú, y sus nodos de vinculación.

Cementerio: El Cementerio, la Capilla de la Sagrada Familia y La Plaza Rocamora, establecen un área de atracción en el sector sur de la ciudad y el camino a Puerto Ruiz.

Plaza San Martín: El conjunto Capilla y Escuela San José, y la Plaza San Martin, en el eje principal de la calle San Antonio, configuran un ámbito que promueve la expansión del área central, pero en el periodo tratado mantiene ciertas características periféricas.

Estación Gualeguay: El Hito y Nodo Estación Gualeguay, con eje en la calle Ayacucho, el Nodo del Camino del Consorcio y el eje de la calle Gualeguaychú, promueven su formación a partir de la llegada del ferrocarril en 1888.

Hospital San Antonio: Un ámbito incipiente en la periferia, pero sobre el límite norte, próximo al eje de la calle San Antonio y a las rutas de conexión con la región central de la provincia. Camino, Hito y Nodo configuran un área de atracción. 
Sociedad Rural: Los Hitos de La Rural, el Regimiento y la Cárcel, junto al camino de borde, la vinculación con el Puente Pellegrini y la calle Gualeguaychú, definen un ámbito particular periférico que se consolidaría luego como el barrio de la "Sociedad Rural".

\section{Estructura UrBana}

A partir de las cinco categorías de análisis desarrolladas, podemos encontrar en sus vinculaciones múltiples lecturas que nos permiten comprender aspectos socioeconómicos, culturales y de funcionamiento del hecho urbano, brindando al mismo tiempo una idea de la estructura urbana para el recorte temporal en estudio 1783-1920.

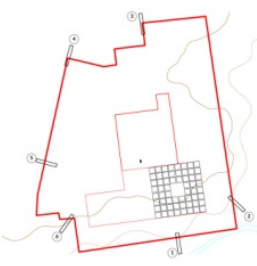

FIGURA 23 A

GRÁFICOS SÍNTESIS: LÍMITES.

FUENTE: ELABORACIÓN PROPIA, DIBUJO DE DANIELA FERNÁNDEZ Y MAYRA RUGGIERO.

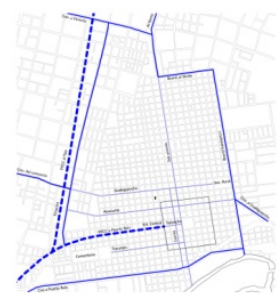

FIGURA 23 B

GRÁFICOS SÍNTESIS: CAMINOS.

FUENTE: ELABORACIÓN PROPIA, DIBUJO DE DANIELA FERNÁNDEZ Y MAYRA RUGGIERO.

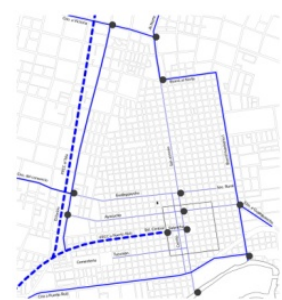

FIGURA $23 \mathrm{C}$

GRÁFICOS SÍNTESIS: NODOS

FUENTE: ELABORACIÓN PROPIA, DIBUJO DE DANIELA FERNÁNDEZ Y MAYRA RUGGIERO.

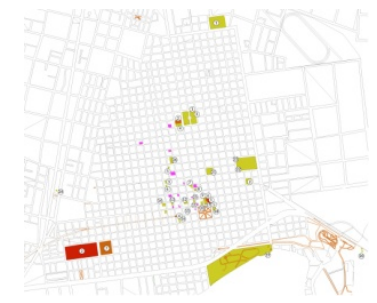

FIGURA 23 D

GRÁFICOS SÍNTESIS: HITOS,

FUENTE: ELABORACIÓN PROPIA, DIBUJO DE DANIELA FERNÁNDEZ Y MAYRA RUGGIERO 


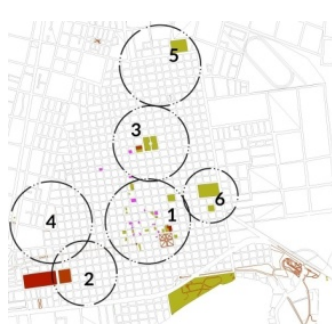

FIGURA $13 \mathrm{E}$

GRÁFICOS SÍNTESIS: ÁMBITOS.

FUENTE: ELABORACIÓN PROPIA, DIBUJO DE DANIELA FERNÁNDEZ Y MAYRA RUGGIERO

Los límites de la ciudad se conformaron a partir de la geometría del trazado fundacional, la presencia del río y su llanura de inundación, la traza del Ferrocarril Gualeguay-Tala y del Ejido Municipal, y de las principales rutas de conexión.

Las vías de conexión fluvial, ferroviaria y caminos, reforzaron los límites y vincularon la ciudad con el exterior, al mismo tiempo que potenciaron las calles internas que conectaban estas vías periféricas con el casco fundacional. La expansión del área central se desarrolló en función de dichas conexiones. Límites y vías principales conformaron una suerte de "recinto" en donde los nodos más significativos se localizaron en los bordes y en el área central.

La gran concentración de hitos que se fueren consolidando dentro de la etapa de estudio, reforzó el área central expandida hacia el cuadrante NO, definiendo un ámbito jerarquizado respecto a los otros ámbitos que surgieron posteriormente a la plaza central.

Cabe señalar las dificultades que transitaron varios de los hitos que tradicionalmente consolidaban el espacio "plaza del pueblo", como la Iglesia, la Municipalidad y la misma plaza, mientras que hoteles, comercios, teatros, escuelas e instituciones, entre otros, se fueron insertando en una nueva área central que ubicó a la plaza Constitución en una esquina del área. En este sentido, las condiciones que establecen las crecidas del río limitaban la expansión hacia el sur y este, pero también, los altos costos del suelo para una economía urbana que mantenía una relación desequilibrada entre las expectativas de crecimiento y las condiciones reales. A partir de 1880 se consolida la ciudad, influenciada por una cierta normalización institucional que promovió a nivel nacional el "...pasaje de lo provisorio a lo permanente... evidenciada, asimismo, en la acción de la elite dirigente para construir un mundo material que diera cuerpo al nuevo Estado nación.” (Schmidt, 2012).

La ciudad de Gualeguay era expresión de ese deseo de consolidación en donde los distintos gruposcolectividades, se afanaban por contribuir a la construcción de esa estructura urbana que definía una ciudad moderna.

\section{A MODO DE CIERRE}

Luego del relevamiento de la información y de su análisis, la metodología nos ayudó a detectar cada uno de los cinco elementos de la estructura urbana, pero muy particularmente nos permitió reunirlos en un único plano que ayuda a reconocer las vinculaciones que existen entre ellos, como se relaciona el todo con las partes y cada elemento con la estructura general, y como esa mirada interescalar nos permite encontrar esa relación medial. 


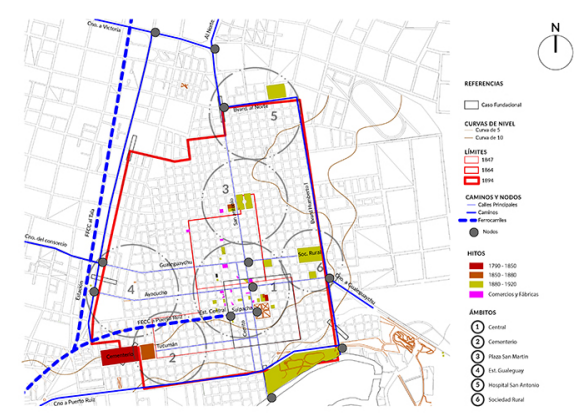

FIGURA 24

GRÁFICO SÍNTESIS ESTRUCTURA URBANA

FUENTE: ELABORACIÓN PROPIA, DIBUJO DE DANIELA FERNÁNDEZ Y MAYRA RUGGIERO.

Los límites naturales y las grandes vías de vinculación exterior, definieron lo urbano y lo rural, los principales caminos de conexión con: muelle, puerto, puente, ferrocarril, área rural y caminos externos, precisaron los ejes principales. La relación entre el cruce de ejes y casco fundacional, definió los nodos que orientan los recorridos en el área central, que, a su vez, son balizados por los hitos urbanos, cargados de contenido simbólico.

Limites, ejes, nodos, e hitos materializan esa "mediación simbólica, cognoscitiva y práctica" que caracteriza a la ciudad y configuran ámbitos diferenciados, que en el período de estudio presentan distintos niveles de consolidación, mientras el área central se encuentra claramente definida, los otros ámbitos van anunciado la aparición de los futuros barrios a partir de ciertos elementos principales de la estructura urbana, el hospital, la estación, la segunda plaza.

En una ciudad emergente como lo fue el Gualeguay de cambio de siglo, surgieron un número significativos de elementos urbanos, que representaban no solo el arribo de la modernización a un enclave periférico, sino también, la generación de un nuevo paisaje urbano nacido de la vinculación entre elementos del legado virreinal y los nuevos habitantes.

A la luz de la nueva patria los habitantes vieron surgir en su pueblo expresiones "gringas", que con el tiempo se convirtieron en símbolos del progreso y de "lo público". Los hitos institucionales, como expresiones modélicas y como condición de posibilidad de lo urbano, se ubicaron en el área central y dieron una nueva imagen a la religión, al gobierno, a la educación, a lo lúdico, a las residencias de los notables, e inclusive a los espacios públicos como calles y plazas. Esos espacios urbanos de distintas escalas, elementos claves de la estructura de la ciudad, se destacaron por su capacidad de ser espacios de mitos, y las diferentes manifestaciones públicas e individuales los utilizaban como ámbitos de sus rituales. Vecinos, calles y edificios, componían así las partes de una representación que contribuía a la construcción de la "nación" desde las nuevas ciudades.

La metodología aplicada nos ayudó a conocer la estructura espacial de la ciudad, y esta nos permitió comprender ciertas relaciones entre el espacio urbano y sus habitantes, esa condensación que define el paisaje.

\section{REFERENCIAS}

Apolinaire, E., Bastourre, L., Costa Angrizani, R. (2016).Arqueología de las tierras altas de Entre Ríos: primeros resultados de las prospecciones en el interior del departamento Gualeguay. Intersecciones en Antropología. 17, 91-107 https://ri.conicet.gov.ar/bitstream/handle/11336/54738/CONICET_Digital_Nro.d649ff1c-b46 a-40a0-b036-dfbb4199b392_A.pdf?sequence=2\&isAllowed=y

Berque, A. (2003). Médiance. Lèvy, J., Lussault, M., Dictionnaire de la Géographie et de L 'Espace des Sociétés. [598-600], Paris: Editorial Belin

Corboz, A. (2015). Orden Disperso: ensayo sobre arte, método, ciudad y territorio. Editorial Universidad de Quilmes 
Diego GaraY*. Gualeguay, LA CONFORMACión De SU PAISAJE ${ }^{[1]}$

Dematteis, G. (2006).En la encrucijada de la Territorialidad Urbana.Revista Bitacora 1, (10), 53 - 63

De Paula, A. (2000), Las Nuevas Poblaciones en Andalucía, California, y el Río de la Plata 1767-1810. Universidad de Buenos Aires. Facultad de Arquitectura, Diseño y Universidad

De Terán, F. et al (1989). La ciudad Hispanoamericana. El Sueño de un Orden. Editorial CEHOPU.

Diario "El supremo" (1983). Suplemento especial del Bicentenario de la Fundación de Gualeguay .

Entre Ríos. Gobierno (1911).El Estado de Entre Ríos. Álbum gráfico y exposición sintética de sus elementos de progreso, Ed. Prov. de Entre Ríos.

Entre Ríos. Turismo (25 de noviembre 2020). Museo de Gualeguay. https://www.turismoentrerios.com/gualeguay/ museos.htm

Favelukes, G., (2011). Figuras y Paradigmas. Las Formas de Buenos Aires (1740-1870), Anales del Instituto de Arte Americano, 41, (1), 11-26.

Forman, T., Dramstad, W.,Olson, J.,(1996). Landscape ecology principles in landscape architecture and land-use planning. Editorial Island Press

INTA. (2014) Carta de Suelos de Entre Ríos. http://www.geointa.inta.gob.ar/2014/04/22/cartas-de-suelos-de-entre -rios/

INTA (25 de noviembre de 2020). Visor GEOinta. http://visor.geointa.inta.gob.ar/?p=136

Lynch, K., (2008). La imagen de la ciudad [Traducido al castellano de The Image of the city]. Editorial Gustavo Gilli.

Massoni, O. (1984). El aporte inmigratorio. Gualeguay 1765 - 1900. Editorial Colmegna.

Mc Harg, I., (2000). Proyectar con la naturaleza [Traducido al castellano de Design with Nature]. Editorial Gustavo Gilli.

Piaggio (9 de septiembre 2012). La inauguración de la sucursal del Banco Italia. El debate Pregón. https://www.diario debatepregon.com/la-inauguracion-la-sucursal-del-banco-italia-n249

Rampoldi, N., Piaggio, C., Gabriel, D., \& Miguez Iñarra, P., (2002) Espacios Públicos con Historia Gualeguay. Editorial Del Clé.

Segura, J. (1971). Tomas de Rocamora: Soldado y Fundador de Pueblos, [s.e.].

Schmidt, C. (2012). Palacios sin reyes: arquitectura pública para la" capital permanente": Buenos Aires, 1880-1890. Prohistoria Ediciones.

Vico, H. (1972). Historia de Gualeguay (Desde sus origenes hasta 1910). Editorial Colmegna.

Wentzel, C., (1988). El comercio del Litoral de los ríos con Buenos Aires: El área del Paraná 1783-1821, Anuario del IEHS, 3. http://anuarioiehs.unicen.edu.ar

Yi-Fu Tuan, (2007). Topofilia. [Traducido al castellano de Topophilia.] Editorial Melusina

\section{REFERENCIAS}

Wikimedia Commons (25 November 2014). Plano fundacional Gualeguaychuhttps://commons.wikimedia.org/wiki /File:Plano_fundacional_de_gualeguaychu.jpg

\section{Notas}

* Arquitecto (UBA) y Magister en Paisaje, Medio Ambiente y Ciudad, UNLP - Programa Alfa-Red Pehuen/Comunidad Europea, (2012).Doctorando en Estudios Urbanos en la UNGS (2015), tesis en elaboración. Actualmente ejerce la docencia en el grado y posgrado, e investigación, en el Instituto de Arquitectura de la UNSAM.

[1]Este artículo se elaboró en el marco del proyecto de investigación PICT N²015-3831, "Historia y patrimonio de la Argentina moderna. Inmigración, transferencia y readaptación de saberes en las dimensiones simbólicas y materiales de los teatros del litoral rioplatense y su conservación,” IR: Fernando Devoto, FONCYT. 2016-2019.

[2] La orden Jesuita fue expulsada del territorio español en 1767 por orden del Rey Carlos III. 
[3] “...Atendiendo pues a la pluralidad de la gente y a lo desierto que se halla esa parte, se puede formar allí una parroquia que comprenda desde la costa del Uruguay hasta la del Paraná, y desde el río Gualeguay hasta el Salto...” (De Paula, 2000).

[4] La primera capilla levantada por los vecinos en 1775, próxima al nuevo emplazamiento, era dedicada a San Antonio y dependiente de la Parroquia de La Bajada (Paraná).

[5] Llamamos límites a aquellos elementos que están constituidos por conformaciones naturales o antrópicas y definen áreas diferenciadas. Por otra parte, estas áreas diferenciadas, pueden vincularse en puntos específicos que denominamos pasos (puentes, "puertas"). Muchas veces ese límite, puede ser materializado y nos permite visualizar que los límites son interrupciones en ciertas continuidades, sobre todo espaciales, sin embargo, son áreas de significativos intercambios y vinculaciones.

[6] Este elemento de la estructura se refiere a las vías de comunicación entre puntos significativos (hitos y nodos) consolidados o entre aquellos que se encuentran en proceso de constituirse como tal. Su materialización resulta de criterios geográficos, técnicos, político-económicos y culturales, pueden ser senderos, caminos, rutas, calles, vías férreas y fluviales.

[7] En el año 1905 entraron a Puerto Ruiz 111 buques ( 92 a vapor +19 a vela) con 40 mil Tn de carga y en 1911 salieron de Puerto Ruiz 166 buques ( 88 a vapor +78 a vela) y entraron 167 buques ( 88 a vapor +79 a vela), (Vico, 1972)

[8] Nos referimos a aquellos cruces, giros o cambios en la dirección de los caminos, que implican sitios de referencia que jerarquizan la red de circulación, resultando elementos vitales para su funcionamiento. Encuentro entre curso de agua y camino, vías férreas y camino o dos caminos, se convierten en nodos al ser una referencia en la circulación. Son las postas en el camino o los puertos en la navegación, que proveen a la circulación de orientación, información, provisiones, control e intercambio. De acuerdo a la escala de análisis, puede una ciudad ser un nodo en la estructura de una región o una esquina ser un nodo en la escala de un barrio.Los nodos son confluencias y concentración de actividades, pero su característica es eminentemente funcional más que representativa, como sí lo son los hitos, aunque pueden coincidir.

[9] Son enclaves de distintas escalas espaciales, que adoptan jerarquía a partir de funciones económicas, políticas y/o culturales, dentro de la estructura que organiza el territorio. Pueden ser materializados con monumentos u otros símbolos conmemorativos, con edificios significativos de diversas escalas, sitios tales como plazas, o encuentro entre arterias jerarquizadas. Siempre tienen un valor simbólico para los habitantes del territorio. Suelen ser confundidos con los Nodos, de los que se diferencia por su valor identitariopara la cultura local. La localización de los hitos ayuda a identificar zonas, como también, a reconstruir la historia local refiriendo a actores y acontecimientos que narran la construcción simbólica del territorio.

[10]En la primera década del siglo XX fue reemplazado el copón de Urquiza por la estatua de la "Constitución".

[11] "Desde 1853 a Gualeguay se la considerará como un importante centro ganadero y comercial, su población se aproximaba a los 6.000 habitantes.", (Masoni, 1982, pp. 17)

[12] Son aquellas áreas que se identifican por ciertas características particulares y rasgos identitarios, denominados barrios o ámbitos. Su propia historia, los grupos sociales que lo habitan, ciertos acontecimientos y sus expresiones físicas, como los nodos e hitos, definen su presencia consolidada o en proceso de.

[13] Ejido: 1869: 7.200 hab. / 1888: 11.973 hab. / 1914: 12.655 / 1922: 16.000.Departamento: 1879: 18.289 hab. / 1893: 20.510 hab. (Vico, 1972, 264) 